\title{
Effects of Nerve Growth Factor (NGF) in Rats with Basal Forebrain Lesions
}

\author{
Shin-ichi Ogawa $\mathbf{a}^{1}$, Toshitaka Nabeshima ${ }^{1,2, *}$, Tsutomu Kameyama ${ }^{1}$ and Kyozo Hayashi ${ }^{3}$ \\ ${ }^{2}$ Department of Chemical Pharmacology, Faculty of Pharmaceutical Sciences, Meijo University, Nagoya 468, Japan \\ ${ }^{2}$ Department of Neuropsychopharmacology and Hospital Pharmacy, Nagoya University School of Medicine, Nagoya 466, Japan \\ ${ }^{3}$ Department of Molecular Biology, Gifu Pharmaceutical University, Gifu 502, Japan
}

Received August 27, 1992 Accepted December 18, 1992

\begin{abstract}
Effects of nerve growth factor (NGF) on the basal forebrain (BF) lesion-induced amnesia in rats were investigated. When NGF infusion was begun immediately after the formation of BF lesions, NGF ameliorated amnesia in a water maze task and showed a tendency to increase choline acetyltransferase (CAT) activity in the fronto-parietal cortex. The amnesia and the decrease of CAT activity were not ameliorated when NGF infusion was begun 4 weeks after BF lesion formation. These observations suggest that NGF may act as a trophic and/or a protective factor on partially damaged cholinergic neurons and that the efficacy of NGF was influenced by the phase of neuronal damage.
\end{abstract}

Keywords: Nerve growth factor (NGF), Choline acetyltransferase (CAT), Water maze

The symptoms of senile dementia and Alzheimer's disease have been suggested to be at least related to the degeneration of cholinergic neurons in the nucleus basalis of Meynert (basal forebrain: BF) in humans, although other neurochemical changes are also observed (1). The primary clinical manifestation is a progressive deterioration of memory (2). Despite substantial effort, the cognitive and behavioral consequences of cholinergic pathology in Alzheimer's disease remain unknown. Studies have been conducted in a search for drugs to treat the cognitive impairment of Alzheimer's disease (3, 4). However, clinically no drugs presently used are fully satisfactory. Nerve growth factor (NGF) has been reported to prevent neuronal death of cholinergic cells (5) and to stimulate cholinergic activity (6). NGF increases the size of acetylcholinesterase-positive cells in areas of the BF, and it enhances the learning behavior of aged rats (7). NGF may be important in the maintenance of the central cholinergic neurons (8). Thus NGF is an interesting substance. However, it is not known whether the efficacy of NGF on central cholinergic damage and cognitive impairment changes when the administration schedule varies in relation to the phase of neuronal damage. In this study, we determined the effects of NGF on the amnesia induced by

\footnotetext{
* To whom correspondence should be addressed ${ }^{(2)}$.
}

BF lesions in rats using a water maze when NGF was given immediately or four weeks after BF lesions to ascertain if the time of administration influenced the ecfficacy of NGF treatment.

Male Wistar rats were anesthetized with pentobarbital $\mathrm{Na}(40 \mathrm{mg} / \mathrm{kg}$, i.p.) and fixed on a stereotactic apparatus. Bilateral lesions were produced by ibotenic acid $(5 \mu \mathrm{g} /$ $0.5 \mu \mathrm{l} / \mathrm{side}$ ) (3) in the BF (P $1.5 \mathrm{~mm}, \mathrm{~L} 2.8 \mathrm{~mm}$ to the bregma, $\mathrm{H} 7.2 \mathrm{~mm}$ below the dura) according to the stereotaxic atlas (9). Sham-operated rats similarly received buffered saline. A 21-gauge stainless steel cannula was placed in the lateral ventricle. A two-week infusion minipump (Alzet 2002, Alza Co.) was implanted subcutaneously for 2 weeks immediately after BF-lesioning (for early infusion) or 4 weeks after BF-lesioning (for late infusion). The minipump was filled with $7 \mathrm{~s}-\mathrm{NGF}$ (daily dose and infusion rate: 0.12 or $0.36 \mu \mathrm{g} /$ day and 0.5 $\mu \mathrm{l} / \mathrm{hr})$ or cytochrome $\mathrm{C}(0.36 \mu \mathrm{g} / \mathrm{day}$ and $0.5 \mu \mathrm{l} / \mathrm{hr})$ in $0.1 \mathrm{mg} / \mathrm{ml}$ bovine serum albumin solution. A circular water tank, $140 \mathrm{~cm}$ in diameter, was used in this study (3). A platform, $10 \mathrm{~cm}$ in diameter, was placed inside the tank, and the upper surface of the platform was $2 \mathrm{~cm}$ below the surface of the water. During each trial, we recorded the time it took to escape onto the platform within 200 sec (escape latency time). The rats performed the water maze task beginning ten days following implantation of 
the pump. Each rat was trained for five consecutive days, and two trials performed on each day. We assayed choline acetyltransferase (CAT) activities in the frontoparietal cortex, hippocampus, and striatum (10). Rats were decapitated one day after they had completed the final trial. CAT activity was measured by a modification of the method of Fonnum (11) using $\left[{ }^{3} \mathrm{H}\right]$-acetyl-Co A $(4.0 \mathrm{mCi} / \mathrm{mmol})$. Protein was measured by the method of Lowry et al. (12).

On the first day of training, the escape time in the sham-operated group did not differ significantly from those in the BF-lesioned groups. However, with repeated training, the escape time in the BF-lesioned groups shortened gradually, while those in the sham-operated group shortened rapidly. Swimming speed during the 10 trial blocks did not differ among groups. The behavioral trace pattern revealed that the rats with the BF lesion swam around the side wall of the pool and did not approach the platform. The rats given the infusion of NGF $(0.36$ $\mu \mathrm{g} /$ day for 2 weeks) at the early lesion phase showed several approaches to the platform and a decrease in the prolonged escape latency induced by the $\mathrm{BF}$ lesion on the 10th trial (Fig. 1, $\mathrm{F}(2,182)=3.385, \mathrm{P}<0.05)$. Although an early infusion of NGF at $0.36 \mu \mathrm{g} /$ day enhanced the acquisition of the spatial task, the administration of a low dose of NGF $(0.12 \mu \mathrm{g} /$ day $)$ failed to produce an enhancement of this. In contrast, the infusion of NGF $(0.36$

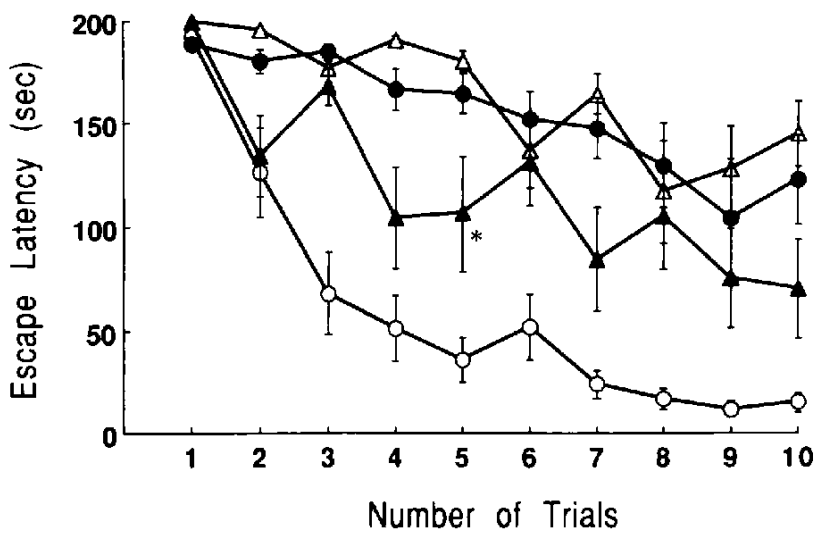

Fig. 1. Effect of nerve growth factor (NGF, immediate postoperative infusion; 0.12 and $0.36 \mu \mathrm{g} / \mathrm{day}$ for 2 weeks, i.c.v.) on amnesia in rats induced by a basal forebrain (BF) lesion: results of the water maze task. NGF infusion was begun immediately after the $\mathrm{BF}$ lesion. The rats were trained in the water maze task beginning 10 days after the continuous infusion of NGF. Groups are as follows: $O$, sham-operated $(\mathrm{N}=5) ; \triangle, \mathrm{BF}$-lesioned $(\mathrm{N}=6) ; \mathrm{O}, \mathrm{BF}$-lesioned and NGF $(0.12 \mu \mathrm{g} /$ day for 2 weeks $)$-treated $(\mathrm{N}=7) ; \boldsymbol{\Delta}, \mathrm{BF}$-lesioned and NGF $(0.36 \mu \mathrm{g} /$ day for 2 weeks)-treated $(\mathrm{N}=7)$. Acquisition data were analyzed using a two-way repeated analysis of variance (ANOVA) design. A level of $P<0.05$ was accepted as statistically significant, followed by the Scheffe test. $F(2,182)=3.385, P<0.05$, ANOVA. ${ }^{*} \mathrm{P}<0.05$ vs. the BF-lesioned group. $\mu \mathrm{g} /$ day) at the late lesion phase failed to improve the rats' performance (Fig. 2). It should be noted that the water maze task could detect a change in behaviors in the acquisition of the spatial proficiency task. The NGF-treated rats displayed an improved swimming strategy. NGF appeared to alter the swimming pattern and thereby enhance the probability that the rats would find the goal and subsequently learn the task. The strategies of the sham-operated and NGF-treated rats were similar, in that they reduced their escape times by swimming away from the wall, i.e., increasing the percentage of the distance they traveled in the area of the platform. NGF increased the activity of the swimming performance, although NGF did not increase general locomotor activity. None of the lesioned rats developed this advanced strategy. A significant decrease in CAT activity was observed in the fronto-parietal cortex of the BF-lesioned group versus the sham-operated group $(\mathrm{P}<0.05)$ (Table 1$)$. The decrease of CAT activity in the hippocampus and striatum was not significant. The early infusion of NGF $(0.36 \mu \mathrm{g} /$ day $)$ tended to increase CAT activity in a dose-dependent fashion, and it increased the CAT activity to $84 \%$ that of the sham-operated group $(\mathrm{F}(2,17)=4.52,0.05<\mathrm{P}<0.1)$. However, the late infusion of NGF failed to reverse the decreased CAT activity. If larger doses of NGF reversed the behavioral dysfunction more completely, larger doses of NGF might significantly restore cholinergic enzyme activity.

Apple has introduced the hypothesis that memory dysfunction and development of senile dementia and Alzhei-

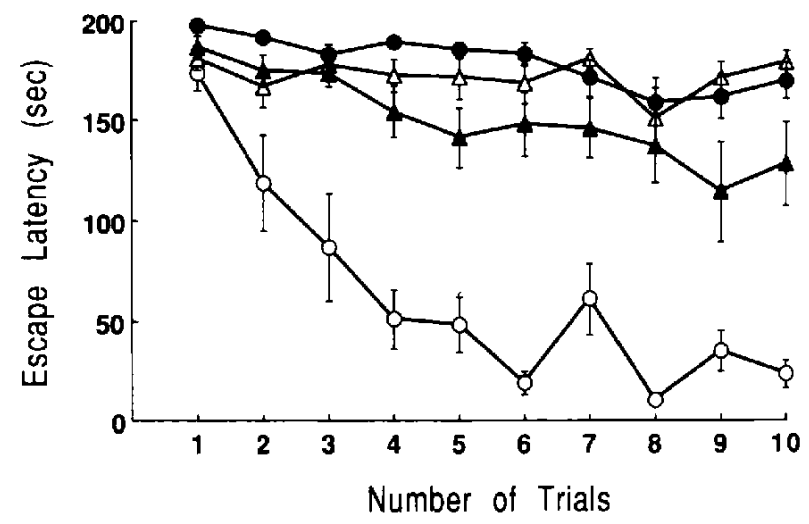

Fig. 2. Effect of nerve growth factor (NGF, infusion delayed until 4 weeks postoperatively; 0.12 and $0.36 \mu \mathrm{g} /$ day for 2 weeks, i.c.v.) on amnesia in rats induced by a basal forebrain (BF) lesion: results of the water maze task. NGF infusion was begun 4 weeks after the BF lesion. The rats were trained on the water maze task beginning 10 days after the continuous infusion of NGF. Groups are as follows: $\bigcirc$, sham-operated $(\mathrm{N}=6)$; $\triangle$, BF-lesioned $(\mathrm{N}=8)$; $\mathrm{O}$, BFlesioned and NGF $(0.12 \mu \mathrm{g} /$ day for 2 weeks)-treated $(\mathrm{N}=8) ; \boldsymbol{\Lambda}, \mathrm{BF}$ lesioned and NGF $(0.36 \mu \mathrm{g} /$ day for 2 weeks)-treated $(\mathrm{N}=8)$. 
Table 1. Effect of nerve growth factor (NGF, immediate postoperative infusion or 4 weeks postoperative infusion; 0.12 and $0.36 \mu \mathrm{g} /$ day for 2 weeks, i.c.v.) on the decrease in choline acetyltransferase (CAT) activity (ACh $\mathrm{nmol} / \mathrm{hr} / \mathrm{mg}$ protein) in the fronto-parietal cortex induced by the basal forebrain $(\mathrm{BF})$ lesion in rats

\begin{tabular}{lll}
\hline Treated & Eariy infusion & Late infusion \\
\hline Sham-operated & $48.5 \pm 1.7$ & $40.1 \pm 2.6$ \\
BF-lesioned & $34.9 \pm 2.3(72.0 \%)^{*}$ & $27.1 \pm 3.6(67.6 \%)^{*}$ \\
$\quad+$ NGF $(0.12 \mu \mathrm{g} /$ day $)$-treated & $36.6 \pm 0.9(75.5 \%)^{*}$ & $27.6 \pm 1.7(68.8 \%)^{*}$ \\
$\quad$ + NGF $(0.36 \mu \mathrm{g} /$ day $)$-treated & $40.6 \pm 1.9(83.7 \%)^{*}$ & $29.3 \pm 1.9(73.1 \%)^{*}$ \\
\hline
\end{tabular}

Biochemical data were analyzed using a parametric one-way analysis of variance. A level of $\mathrm{P}<0.05$ was accepted to indicate statistically significane, followed by the Scheffe test. Results are given as the mean \pm S.E. ( $\%$ of the sham-operated), ${ }^{*} \mathrm{P}<0.05$ vs. the sham-operated group.

mer's disease may be related to a deficiency in the supply or utilization of neurotrophic factors (8). This hypothesis is strengthened by recent findings showing the presence of both NGFmRNA and NGF receptor molecules in the central nervous system of humans and adult rats $(13,14)$. Lower levels of NGF and NGFmRNA are observed in the cortex and hippocampus of aged rats as compared with young rats. NGF-treated aged rats improved behavior and displayed an increased size of acetylcholinesterasepositive cells in the BF as compared to the age-matched controls (7). Furthermore, we previously reported that treatment of rats with anti-NGF-antibody impairs their learning ability and that the nuclei of cells in the hippocampus and cortex were unevenly stained with hematoxylin (15). However, there is no direct evidence to implicate a causal role of an altered level of neurotrophic factor in either normal aging or in the acceleration of a neurodegenerative process.

We propose that the continuous presence of high doses of NGF as used in the present experiment might prevent the early phenomena of the degeneration of cholinergic neurons. Our findings suggest that the infused NGF is taken up by the cortical cholinergic neurons and by the axons of the basal nucleus of Meynert-cortex cholinergic neurons, and that the NGF promotes the survival of a subpopulation of the BF neurons that had undergone retrograde degeneration induced by ibotenic acid. The finding that NGF can rescue central neurons from ibotenic acidinduced degeneration has implications for understanding neuro-degenerative disease. On the other hand, late infusion of NGF did not influence the cognitive dysfunction and the decreased CAT activity. In this case, the cells damaged by ibotenic acid might be led to neuronal death, and the damaged cells might have been rescued by NGF when NGF was given at the early phase of neuronal damage by ibotenic acid. These data suggest that NGF might not have been able to attenuate the amnesia and the decrease of CAT activities at the late phase of neuronal damage when the neuronal cells were strongly damaged. Thus, the rescue of damaged cholinergic neurons by NGF may lead to novel therapeutic approaches to dementia. Finally the problems of applying NGF-like peptides as therapeutic drugs clinically should be noted, since they are not able to pass through the blood-brain barrier, and they are easily degraded by peptidases in the peripheral route. Further studies are needed to clarify the relationship between NGF and dementia.

\section{REFERENCES}

1 Gottfries, C.G.: Alzheimer's disease and senile dementia: biochemical characteristics and aspects of treatment. Psychopharmacology (Berlin) 86, 245-252 (1985)

2 Etienne, P., Robitaille, Y., Wood, P., Gauthier, S., Nair, N.P.V. and Quirion, R.: Nucleus basalis neuronal loss, neuritic plaques and choline acetyltransferase activity in advanced Alzheimer's disease. Neuroscience 19, 1279-1291 (1986)

3 Nabeshima, T., Ogawa, S., Nishimura, H., Fuji, K., Kameyama, T. and Sasaki, Y.: Staurosporine facilitates recovery from the basal forebrain-lesion-induced impairment of learning and deficit of cholinergic neuron in rats. J. Pharmacol. Exp. Ther. 257, 562-566 (1991)

4 Nabeshima, T., Yoshida, S. and Kameyama, T.: Effects of the novel compound NIK-247 on impairment of passive avoidance response in mice. Eur. J. Pharmacol. 154, 263-269 (1988)

5 Kromer, L.F.: Nerve growth factor treatment after brain injury prevents neuronal death. Science 235, 214-216 (1987)

6 Martínez, H.J., Dreyfus, C.H., Jonakait, G.M. and Black, I.B.: Nerve growth factor selectively increases cholinergic markers but not neuropeptides in rat basal forebrain in culture. Brain Res. 412, 295-301 (1987)

7 Fischer, W., Wictorin, K., Björklund, A., Williams, L.R., Varon, S. and Gage, F.H.: Amelioration of cholinergic neuron atrophy and spatial memory impairment in aged rats by nerve growth factor. Nature 329, 65-68 (1987)

8 Appel, S.H.: An unifying hypothesis for the cause of amyotrophic lateral sclerosis, parkinsonism, and Alzheimer disease. Ann. Neurol. 10, 499-503 (1981)

9 Paxinos, G. and Watson, C.: The Rat Brain in the Stereotaxic Coordinates. Academic Press, New York (1986) 
10 Glowinski, J. and Iversen, L.: Regional studies of catecholamines in the rat brain-I, the disposition of $\left[{ }^{3} \mathrm{H}\right]$ dopamine and $\left[{ }^{3} \mathrm{H}\right]$ dopa in various regions of the brain. J. Neurochem. 13, $655-669$ (1966)

11 Fonnum, F.: A rapid radiochemical method for the determination of choline acetyltransferase. J. Neurochem. 24, 407-409 (1975)

12 Lowry, O.H., Rosebrough, H.J., Farr, A.L. and Randall, R.J.: Protein measurement with the Folin phenol reagent. I. Biol. Chem. 193, 265-275 (1951)

13 Hefti, F., Hartikka, J., Salvatierra, A., Weiner, W. and Mash,
D.C.: Localization of nerve growth factor receptors in cholinergic neurons of the human basal forebrain. Neurosci. Lett. 69, $37-41$ (1986)

14 Whittemore, S.R. and Seiger, A.: The expression, localization and functional significance of $\beta$-nerve growth factor in the central nervous system. Brain Res. Rev. 12, 439-464 (1987)

15 Nabeshima, T., Ogawa, S., Ishimaru, H., Kameyama, T., Fukuta, T., Takeuchi, R. and Hayashi, K.: Memory impairment and morphological changes in rats induced by active fragment of anti-nerve growth factor-antibody. Biochem. Biophys. Res. Commun. 175, 215-219 (1991) 